\title{
Histopathological evaluation of colonic mucosal biopsy specimens in chronic inflammatory bowel disease: diagnostic implications
}

\author{
C A Seldenrijk, B C Morson, S G M Meuwissen, N W Schipper, J Lindeman, C J L M Meijer
}

\begin{abstract}
In a prospective blind evaluation of multiple colonic mucosal biopsy specimens, 45 clinically well defined patients with chronic inflammatory bowel disease ( 21 Crohn's disease and 24 ulcerative colitis) and 16 control subjects (seven normal subjects and nine patients with diverticular disease) were studied to identify reproducible histopathological features which could distinguish chronic inflammatory bowel disease (CIBD) from non-CIBD and Crohn's disease from ulcerative colitis. Using kappa statistics 16 of 41 histological features were sufficiently reproducible for further stepwise discriminant analysis to differentiate between CIBD and non-CIBD, and between Crohn's disease and ulcerative colitis. Using the combination of three features (an increase of lymphocytes and plasma cells in the lamina propria, the presence of branching of crypts, and neutrophils in the crypt epithelium) we were able to distinguish CIBD from non-CIBD in $89 \%$ of the cases with high probability ( $p>0.85)$. To separate Crohn's disease from ulcerative colitis three features (an excess of histiocytes in combination with a villous or irregular aspect of the mucosal surface and granulomas) had a high predictive value. Using these features $\mathbf{7 0 \%}$ of Crohn's disease patients and $75 \%$ of ulcerative colitis patients were correctly classified with a high probability $(p>0.85)$. These findings indicate that the pathologist is dependent on the presence of only a few histological features for a reliable classification of Crohn's disease and ulcerative colitis.
\end{abstract}

C A Seldenrijk

N W Schipper

C J L M Meijer

and Department of

Gastroenterology, Free

University Hospital of

Amsterdam

S G M Meuwissen

Department of

Pathology, Slotervaart

Hospital, Amsterdam,

The Netherlands

$\mathrm{J}$ Lindeman

Department of

Pathology, St Mark's

Hospital, London, UK

B C Morson

Correspondence to:

CA Seldenriik, Department of

Pathology, Free University

Hospital of Amsterdam, De

Boelelaan 1117, $1007 \mathrm{MB}$,

Amsterdam, The

Netherlands.

Accepted for publication

21 January 1991 and ulcerative colitis should be based on dis criminating histological features which are sufficiently reproducible. ${ }^{10}$ Assessment of observer variation may identify diagnostic problem areas and may have great therapeutic consequences in clinical practice. ${ }^{10-13}$ However, few studies have been carried out in which the reproducibility and diagnostic value of histopathological features in the differential diagnosis of Crohn's disease and ulcerative colitis have been investigated. ${ }^{1+17}$

We performed a prospective blind evaluation of a large number of histopathological features in multiple colonic biopsy specimens from patients with clinically well defined CIBD to accomplish three main objectives: (i) to assess the reproducibility of the histological features commonly used in the histopathological evaluation of colonic mucosal biopsy specimens; (ii) to determine which combination of features has the highest discriminative power in distinguishing CIBD from non-CIBD; (iii) to determine in patients classified as having CIBD which combination of histological features has the highest diagnostic value in distinguishing between Crohn's disease and ulcerative colitis.

\section{Methods}

The evaluation was made on a total of 61 patients: 45 patients with CIBD (Crohn's disease or ulcerative colitis) and 16 control subjects.

\section{PATIENTS WITH CIBD}

Twenty one patients with Crohn's disease (seven men, 14 women; mean age 31.4 years, range 21 62 years) and 24 patients with ulcerative colitis (14 men, 10 women; mean age 40 years, range 15-70 years) were included in this study. The diagnosis of Crohn's disease was based on well established clinical, endoscopic, and radiological parameters. Features characteristic of Crohn's disease: perianal pathology, distal ileum involvement, fistulas, eccentric involvement of the colon, serpiginous or longitudinal ulcers, fissures, cobblestones, and skip lesions. Criteria were comparable with those proposed by Surawicz and Belic. ${ }^{1+}$

The clinical diagnosis of ulcerative colitis was based on a characteristic history of recurrent blood/mucus loss, mucosal abnormalities/ friability, and loss of yascular architecture, mucopurulent material covering the mucosa, and lesions increasing in severity towards the rectoanal canal, often supported by radiological findings, consistent with a diagnosis of ulcerative colitis. Faecal cultures were all negative for Salmonella, Shigella, Yersinia, and Campylobacter. No antibiotics had been prescribed previously except salazosulphapyridine. The majority of the cases are under regular surveillance in our outpatient department and no change 
in diagnosis was necessary later at clinical follow up. Patients with doubtful criteria (indeterminate colitis) were not included in the study.

All these clinically defined patients with typical Crohn's disease and ulcerative colitis had a colonoscopy or sigmoidoscopy and multiple biopsy specimens were taken, usually from descending colon, sigmoid, and rectum, and if possible from transverse and ascending colon (Table I). At least three biopsy specimens were taken from each site. Therefore usually nine specimens per patient were studied from the nine to 15 specimens taken. Specimens were taken from inflamed mucosa (when present), not from ulcer margins or ulcer debris.

The clinical activity of the disease was determined according to the Sutherland score for ulcerative colitis ${ }^{18}$ and the Harvey-Bradshaw score ${ }^{19}$ for Crohn's disease.

TABLE I Biopsy site in patients with Crohn's disease, ulcerative colitis, and diverticular disease and in healthy control subjects

\begin{tabular}{lllll}
\hline \multicolumn{5}{l}{ Clinical diagnosis } \\
\cline { 2 - 5 } Site & $\begin{array}{l}\text { Crohn's } \\
\text { disease } \\
(n=21)\end{array}$ & $\begin{array}{l}\text { Ulcerative } \\
\text { colitis } \\
(n=24)\end{array}$ & $\begin{array}{l}\text { Diverticular } \\
\text { disease } \\
(n=9)\end{array}$ & $\begin{array}{l}\text { Normal } \\
(n=7)\end{array}$ \\
\hline $\begin{array}{l}\text { Rectum, sigmoid } \\
\text { Rectum, transverse colon }\end{array}$ & 2 & 3 & - & - \\
$\begin{array}{l}\text { Transverse, ascending colon } \\
\text { Rectum, sigmoid, descending colon }\end{array}$ & 1 & - & - & - \\
$\begin{array}{l}\text { Rectum, descending, transverse colon } \\
\text { Rectum, sigmoid, descending, transverse } \\
\text { colon }\end{array}$ & 9 & 1 & 7 & 7 \\
$\begin{array}{l}\text { Rectum, sigmoid, descending, transverse, } \\
\text { ascending colon }\end{array}$ & 4 & $\overline{7}$ & $\overline{2}$ & - \\
\hline
\end{tabular}

TABLE II Histological features used in the evaluation of colonic biopsy specimens from patients with CIBD and control subjects

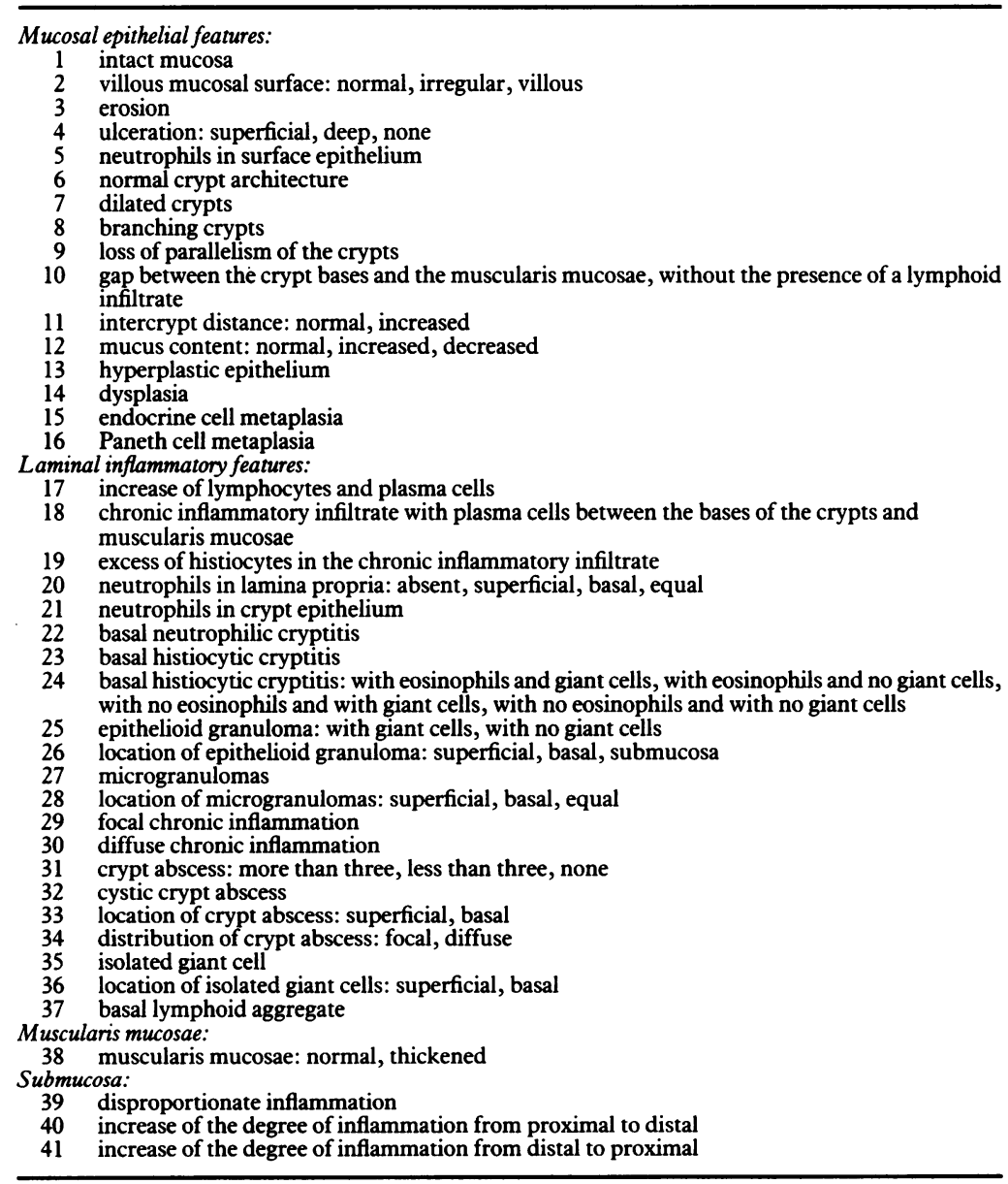

\section{CONTROL SUBJECTS}

The control group $(n=16)$ comprised nine patients with diverticular disease (six men, three women; mean age $69 \cdot 4$ years, range $56-86$ years) and seven healthy control subjects (two men, five women; mean age $57 \cdot 6$ years, range $28-75$ years) who were seen during follow up for resection of polyps. All had sigmoidoscopy, and multiple biopsy specimens were taken from descending colon, sigmoid, and rectum. All faecal cultures were negative.

\section{BIOPSY PROCESSING}

Biopsy specimens were fixed in sublimate formaldehyde, paraffin-embedded, cut at $4 \mu \mathrm{m}$, step sectioned, and stained with haematoxylin and eosin. From each biopsy specimen at least three slides, each containing six serial sections, were examined. Biopsy specimens were randomised and coded so that the histological evaluation of the slides was performed without any clinical information.

\section{HISTOLOGIC FEATURES}

On the basis of published data ${ }^{20-25}$ and our own experience we chose 41 histopathological features to evaluate (Table II). We particularly chose qualitative features that can be recognised by the pathologist in daily practice. Before histological evaluation a list of the definitions of the histological features was provided to the four participating pathologists (BCM, CJLM, JL, CAS).

Most of the histological features (Table II) are self explanatory, but a few need to be defined as follows:

Feature 2: a villous mucosal surface $^{14}$ is a surface contour of broad villous like projections with a villous crypt ratio of more than 1.5 (Fig 1A); a mucosal surface with a villous crypt ratio between 1 and 1.5 was considered an irregular surface.

Feature 3: an erosion was diagnosed if neutrophils were present in the base of the area of loss of the surface epithelium; the presence of neutrophils assures that the break in the epithelium is not an artefact produced by biopsy trauma.

Feature 4: an ulceration was deep if it extended into the submucosa.

Feature 8: branching crypts were diagnosed if there was a distorted crypt architecture in which two or more branched crypts in a well orientated biopsy were present. Often this branching is accompanied with shortening of crypts. Branching in the vertical plane could easily be recognised, but branching in the horizontal plane often produced acinar glandular profiles.

Feature 10: another feature of distorted architecture was the presence of an enlarged space between the bottoms of the crypts and the muscularis mucosae with a 'shortfall' of the crypts.

Feature 11: intercrypt distance was increased when mucosa showed a clear loss of the number of crypts.

Feature 14: dysplasia is defined as an unequivocal neoplastic alteration of the colonic epithelium. ${ }^{26}$ 

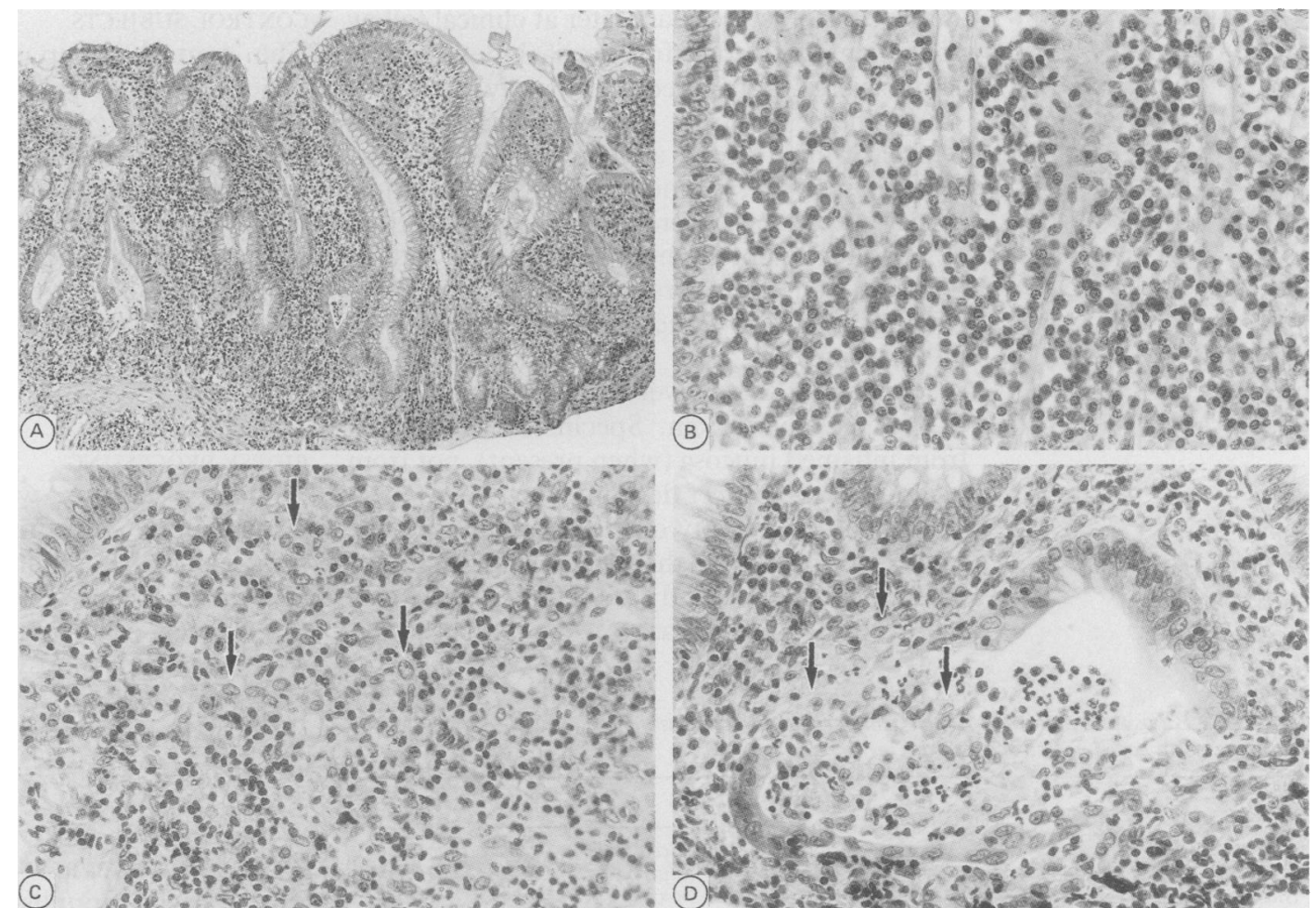

Figure 1: (A) Ulcerative colitis patient: villous surface in a colonic biopsy specimen. (B) Ulcerative colitis patient: non-histiocytic chronic inflammatory infiltrate. (C) Crohn's disease patient: an excess of histiocytes. (D) Crohn's disease patient: basal histiocytic cryptitis. Arrows indicate the histiocytic component.

Feature 17: the number of round cells in the lamina propria of normal colonic biopsy specimens varies widely. Thus it may be difficult to decide when round cell numbers are abnormally increased. Therefore an increase of lymphocytes and plasma cells was diagnosed only if there was an obvious increase in the number these cells; an unequivocal or mild increase was not considered abnormal.

Feature 19: an excess of histiocytes was diagnosed when the chronic inflammatory infiltrate contained a large number of histiocytes, either focal or diffuse (Fig 1B and C).

Feature 20: increase in neutrophils was defined as the presence of more than three neutrophils in the lamina propria; a superficial location was defined as the upper half of the mucosal layer; basal location meant the lower half of the mucosa.

Feature 22: basal neutrophilic cryptitis is present when there is migration of neutrophils into the crypt epithelium with focal lysis of epithelial cells.

Feature 23: basal histiocytic cryptitis ${ }^{22} 25$ was defined as a histiocytic inflammatory infiltrate and was present in the epithelium of the base of a crypt (Fig 1D).

Feature 25: an epithelioid granuloma is a discrete collection of at least five epithelioid cells with or without accompanying giant cells, and without caseating necrosis or foreign bodies.

Feature 27: a microgranuloma is an aggregate of histiocytes and lymphocytes ${ }^{22}$; giant cells are absent in microgranulomas.

Feature 29: the distribution of the chronic inflammation was focal if it had a patchy distribution, in contrast to a diffuse pattern where the inflammation is band like.

Feature 31: a crypt abscess is a chain of neutrophils extending from the lamina propria through the crypt epithelium into the lumen of the crypt.

Feature 32: a cystic crypt abscess is an abscess with flattening of the epithelial cells in a dilated, ballooned gland.

Feature 37: basal lymphoid aggregates ${ }^{9}$ are nodular collections of lymphocytes without reactive centres, located between the muscularis mucosae and the crypts; at least two aggregates had to be present in a biopsy specimen to be considered abnormal.

Feature 39: the inflammation was disproportionate if the submucosa contained a denser infiltrate than the mucosa.

All slides were examined in one session. Each pathologist separately summarised and recorded the histological features on a data file for each patient. All data were entered on a computer file for statistical analysis.

\section{STATISTICAL ANALYSIS}

\section{Reproducibility analysis}

The degree of agreement between observers was characterised by kappa statistics. Kappa is an index of observer agreement which has been corrected for chance and therefore is a measure of the degree of agreement (Program P4F of the BMDP statistical software package $\left.{ }^{27}\right)$. Kappa values greater than 0.75 are considered to represent excellent agreement beyond chance, values below 0.4 poor agreement beyond chance, and values between 0.4 and 0.75 fair to good agreement beyond chance. ${ }^{28}$

Kappa values for interobserver (BCM, CJLM, $\mathrm{JL}, \mathrm{CAS}$ ) agreement were calculated for each of the 41 histopathological features. Features with a 
TABLE III Histological features in colonic biopsy specimens from patients with Crohn's disease, ulcerative colitis, and diverticular disease and control subjects (Percentages in parentheses

\begin{tabular}{|c|c|c|c|c|c|}
\hline & $\begin{array}{l}\text { Healthy } \\
\text { control } \\
\text { subjects } \\
(n=7)\end{array}$ & $\begin{array}{l}\text { Diverticular } \\
\text { disease } \\
(n=9)\end{array}$ & $\begin{array}{l}\text { Crohn's } \\
\text { disease } \\
(n=2 I)\end{array}$ & $\begin{array}{l}\text { Ulcerative } \\
\text { colitis } \\
(n=24)\end{array}$ & $p^{\star}$ \\
\hline \multicolumn{5}{|l|}{ Mucosal surface (2)†: } & \multirow[t]{4}{*}{0.0004} \\
\hline Normal & $7(100)$ & $9(100)$ & $16(76)$ & $5(20)$ & \\
\hline Irregular & $0(0)$ & $0(0)$ & $5(24)$ & $15(63)$ & \\
\hline Villous & $0(0)$ & $0(0)$ & $0(0)$ & $4(17)$ & \\
\hline \multicolumn{5}{|l|}{ Ulceration (4) } & \multirow[t]{3}{*}{$0 \cdot 0022$} \\
\hline Superficial & $0(100)$ & $0(0)$ & $5(24)$ & $2(8)$ & \\
\hline Deep & $0(0)$ & $0(0)$ & $6(29)$ & $6(25)$ & \\
\hline Neutrophils in surface epithelium (5) & $0(0)$ & $1(11)$ & $14(67)$ & $18(75)$ & $0 \cdot 0000$ \\
\hline Normal crypt architecture (6) & $7(100)$ & $8(89)$ & $6(29)$ & $2(8)$ & 0.0000 \\
\hline Dilated crypts $(7)$ & $1(14)$ & $1(11)$ & $3(14)$ & $12(50)$ & $0 \cdot 1134$ \\
\hline Branching crypts $(8)$ & $0(0)$ & $0(0)$ & $14(67)$ & $20(83)$ & 0.0000 \\
\hline Increased lymphocytes, plasma cells (17) & $1(14)$ & $2(22)$ & $20(95)$ & $22(92)$ & 0.0000 \\
\hline $\begin{array}{l}\text { Chronic inflammation with plasma cells } \\
\text { between bases of crypts and the }\end{array}$ & $0(0)$ & $0(0)$ & $13(62)$ & $15(63)$ & 0.0000 \\
\hline $\begin{array}{l}\text { muscularis mucosae (18) } \\
\text { Excess histiocytes in the chronic }\end{array}$ & $0(0)$ & $0(0)$ & $17(81)$ & $3(13)$ & 0.0013 \\
\hline inflammatory infiltrate (19) & (0) & (v) & $17(01)$ & (10) & 8001 \\
\hline Neutrophils in crypt epithelium (21) & $0(0)$ & $0(0)$ & $18(86)$ & $18(75)$ & 0.0000 \\
\hline Basal histiocytic cryptitis (23) & $0(0)$ & $0(0)$ & $8(38)$ & $2(8)$ & $0 \cdot 0408$ \\
\hline \multicolumn{5}{|l|}{ Epithelioid granulomas (25): } & \multirow[t]{3}{*}{$0 \cdot 0416$} \\
\hline With giant cells & $0(0)$ & $0(0)$ & $6(29)$ & $0(0)$ & \\
\hline Without giant cells & $0(0)$ & $0(0)$ & $4(19)$ & $0(0)$ & \\
\hline Focal chronic inflammation (29) & $1(14)$ & $1(11)$ & $19(90)$ & $3(13)$ & \multirow{4}{*}{$\begin{array}{l}0.0111 \\
1.0000\end{array}$} \\
\hline \multicolumn{5}{|l|}{ Distribution of crypt abscesses (34) } & \\
\hline Focal & $0(0)$ & $0(0)$ & $12(57)$ & $4(17)$ & \\
\hline Diffuse & $0(0)$ & $0(0)$ & $1(5)$ & $3(13)$ & \\
\hline $\begin{array}{l}\text { Increase of inflammation from proximal } \\
\text { to distal submucosa }(40)\end{array}$ & $0(0)$ & $0(0)$ & $2(10)$ & $7(29)$ & 0.0547 \\
\hline $\begin{array}{l}\text { Increase of inflammation from distal to } \\
\text { proximal submucosa }(41)\end{array}$ & $0(0)$ & $0(0)$ & $12(57)$ & $2(8)$ & 0.0117 \\
\hline
\end{tabular}

«p value of the univariate analysis (Mann-Whitney) to discriminate between CIBD (Crohn's disease + ulcerative colitis) $v$ non-CIBD (diverticular disease and healthy control subjects). $†$ Numbers as in Table II. with or without eosinophils or with or without giant cells, location of epithelioid granulomas, and presence and location of microgranulomas was too low to investigate their reproducibility by kappa statistics. It is remarkable that the presence of crypt abscesses is not a reproducible observation. We do not have a clear explanation for this finding. It might be that the (sub)classification of the items in the feature - that is, more than three, less than three, or no crypt abscesses - is the cause of the lack of reproducibility. In the study of Surawicz and Belic ${ }^{14}$ the assessment of this feature was reproducible, however.

The 16 reproducible criteria were included for further univariate and multivariate analysis.

\section{UNIVARIATE ANALYSIS}

The results of the univariate analysis of the 16 histological features to differentiate between CIBD and non-CIBD are shown in Table III. Histological features with $\mathrm{p}<0.05$ significantly discriminated between CIBD and non-CIBD. The following features showed the best discrimination in the differential diagnosis of CIBD/non-CIBD $(p<0.0001)$ : neutrophils in surface epithelium, normal crypt architecture, branching crypts, increase in lymphocytes and plasma cells, chronic inflammatory infiltrate between the bases of the crypts and the muscularis mucosae, and neutrophils in crypt epithelium.

mean kappa value of more than 0.4 and at three out of six kappa values of more than 0.4 were considered to be sufficiently reproducible. ${ }^{28}$

\section{Univariate/multivariate analysis}

Histological features with sufficient reproducibility were analysed by univariate and multivariate analysis on all patients $(n=61)$. Univariate analysis was performed for each histological feature separately using the MannWhitney non-parametric test (Programs P3S of the BMDP statistical software package ${ }^{27}$ ). Results with a $p$ value $<0.05$ were regarded as significant.

To determine the combination of histological features giving the best discrimination, firstly, between CIBD and non-CIBD (non-specific chronic inflammation/normal) in the total group of 61 patients, (linear) stepwise discriminant analysis (Program P7M) was carried out. Secondly, a similar analysis was performed to distinguish, in patients with a diagnosis of CIBD, between Crohn's disease and ulcerative colitis.

Evaluation of the discriminant function was performed by classifying specimens of the same set of patients according to the jackknifed classification method. ${ }^{28}$

\section{Results}

\section{REPRODUCIBILITY ANALYSIS}

According to the kappa values 16 of 41 histological features (Table III) were sufficiently reproducible. The frequency of several scored items such as dysplasia, endocrine and Paneth cell metaplasia, basal histiocytic cryptitis either
MULTIVARIATE ANALYSIS

To determine the combination of features useful in differentiating CIBD from non-CIBD, stepwise linear discriminant analysis was carried out. The first histological feature with the highest discriminatory power was the presence or absence of an increase in lymphocytes and plasma cells. The presence or absence of branching crypts provided further discriminative power. Adding a third feature, neutrophils in crypt epithelium, resulted in a more accurate classification.

The results of jackknifed classification with these three histological features are shown in Figure 2. For histopathological diagnosis high a posteriori probabilities are mandatory. Therefore values of 0.15 and 0.85 were selected as cut off points for the probabilities. A patient is predicted to have CIBD when the probability of CIBD is greater than 0.85 and not to have CIBD when the probability is less than $0 \cdot 15$. Both nonCIBD and CIBD patients are recorded as nonclassifiable when the probability lies between 0.15 and 0.85 . Using the combination of these three histological features, 40 of $45(93 \%)$ CIBD patients had 13 of $16(81 \%)$ non-CIBD subjects were correctly classified, as shown in Figure 2. The 40 patients comprised 20 with Crohn's disease and 20 with ulcerative colitis. Three (one Crohn's disease and two ulcerative colitis) of 45 (7\%) CIBD patients were falsely classified as non-CIBD, with a CIBD probability of $\mathrm{p}<0 \cdot 15$. Two CIBD (8\%) patients (ulcerative colitis) and three patients in the non-CIBD group (all with diverticular disease) were recorded as nonclassifiable $(0 \cdot 15 \leq$ probability $\leq 0 \cdot 85)$. 
Figure 2: Fackknifed classification results using the three selected histological features in the total patient population $(n=61)$. The chronic inflammatory bowel disease (CIBD) a posteriori probabilities 0.15 and 0.85 were chosen as cut off points. $+=$ Crohn's disease; $0=$ ulcerative colitis; $X=$ non$C I B D ; P C I B D=a$ posteriori probability of $C I B D$; Pnon-CIBD =a posteriori probability of non pIBD.
Figure 3: Fackknifed classification results using the three selected histological features as in patients with a diagnosis of chronic inflammatory bowel disease $(C I B D)(n=40)$. The ulcerative colitis a posteriori probabilities 0.15 and 0.85 were chosen as cut off points. $+=$ Crohn's disease; $0=$ ulcerative colitis; $P U C=$ a posteriori probability of ulcerative colitis; $P C D=a$ posteriori probability of Crohn's disease.

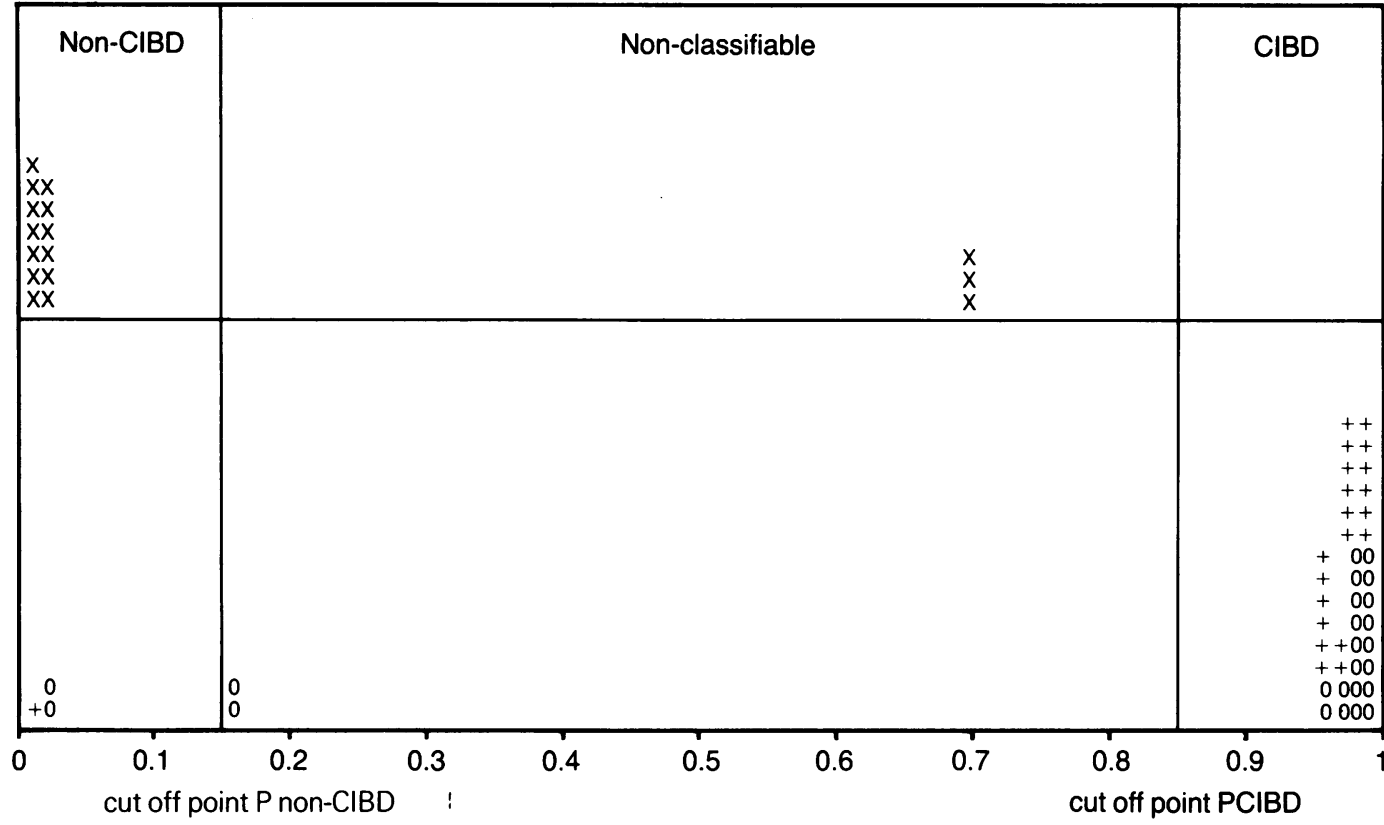

To select the features with the best power of discrimination to distinguish Crohn's disease from ulcerative colitis in the patients classified as CIBD $(n=40)$ a similar stepwise linear discriminant analysis was performed. The most contributive feature was the presence or absence of an excess of histiocytes in the inflammatory infiltrate. A second feature was the aspect of the mucosal surface - normal, irregular, or villous. The additional feature of epithelioid granulomas resulted in a more accurate classification. These three features were tested in the jackknifed classification, as shown in Figure 3.

A patient is predicted to have ulcerative colitis when the a posteriori probability is $>0.05$ and not to have ulcerative colitis, thus Crohn's disease, when the a posteriori probability is $<0 \cdot 15$. Patients with probabilities between or equal to 0.15 and 0.85 were recorded as CIBD indeterminate.

Figure 3 shows that 14 of $20(70 \%)$ patients with Crohn's disease were correctly classified and 15 of $20(75 \%)$ patients with ulcerative colitis were correctly classified, both with probabilities of more than $0 \cdot 85$. Two patients with Crohn's disease were falsely classified as ulcerative colitis with a high probability of more than $0 \cdot 85$. One ulcerative colitis patient was classified as Crohn's disease. Eight of the 40 CIBD patients (20\%) were classified as CIBD indeterminate: four with Crohn's disease and four with ulcerative colitis.

\section{Discussion}

This prospective study on the evaluation of colonic biopsy specimens from CIBD patients shows that, according to kappa statistics, only 16 of 41 histological features were sufficiently reproducible. This finding is important since reproducibility of histological characteristics is seldom evaluated. The application of stepwise discriminant analysis to these 16 histological features to differentiate between CIBD patients and non-CIBD patients identified three dis-

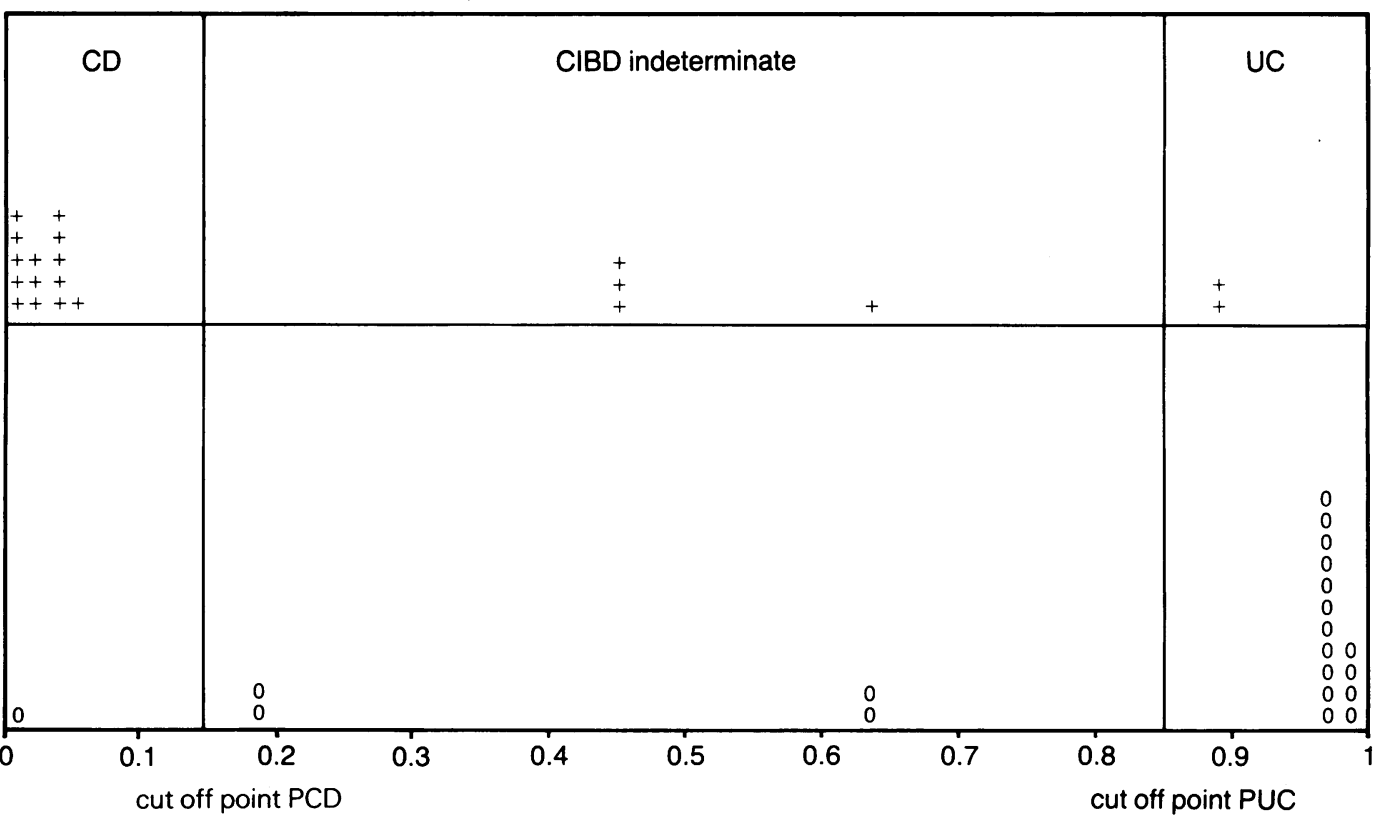


criminating histological features. These were an increase in lymphocytes and plasma cells in the lamina propria, branching of crypts, and neutrophils in the crypt epithelium. With these features 40 of $45(89 \%)$ CIBD patients were correctly classified with a high probability $(p>0 \cdot 85)$. Four (17\%) patients with ulcerative colitis were not classified as ulcerative colitis - that is two were classified as non-CIBD and two were not classifiable. Only one (5\%) Crohn's disease patient was falsely classified as non-CIBD. An explanation for the two ulcerative colitis cases erroneously classified might be the low clinical activity of the disease (Sutherland score below 3); however, the Crohn's disease patient had a clinical activity score of 10 , according to the Harvey-Bradshaw index. To distinguish between Crohn's disease and ulcerative colitis the combination of three histological features had the best discriminating value - that is, an excess of histiocytes, the aspect of the mucosal surface, and epithelioid granulomas.

Few similar studies applying stepwise discriminant analysis to investigate the importance of certain histological features in biopsy specimens to the diagnosis of CIBD have been carried out. ${ }^{29-31}$ In contrast to the studies of Jenkins et $a l$ and Thompson et $a l^{29-31}$ in which a wide range of morphometric measurements were performed, our goal was to determine the features easily found in daily pathology practice. Nevertheless, to some extent the results are comparable and show similarities.

Jenkins $e t ~ a l^{29}$ applied discriminant analysis to multiple variables based on measurements in rectal biopsy specimens only. With the combination of an increase in lamina propria cellularity and the ratios of surface length to mucosal length and of surface epithelial height to crypt epithelial height $95 \%$ of the CIBD cases were distinguished from normal. This is in agreement with our results.

Our finding that an increase in plasma cells and lymphocytes is highly predictive for CIBD has been found by others. ${ }^{14} 2930$

Using conventional histological features such as an excess of histiocytes, the aspect of the mucosal surface, and granulomas, we classified $70 \%$ of the Crohn's disease and $75 \%$ of the ulcerative colitis patients correctly with a high probability ( $p>0.85)$. Using measurements such as the standard deviation of crypt length, intercrypt distance, and the number of polymorphs per unit lamina propria area, Jenkins et al had similar results. ${ }^{29}$ However, their false positive rate for Crohn's disease and ulcerative colitis was higher than ours $-23 \%$ and $28 \%$ compared with $10 \%$ and $5 \%$ in our study.

Our finding that the aspect of the mucosal surface and granulomas are important features for differentiating between Crohn's disease and ulcerative colitis has been reported by others. $^{141617}$

The diagnostic accuracy rates in other studies on the histological evaluation of mucosal biopsy specimens to differentiate Crohn's disease from ulcerative colitis are to some extent similar..$^{30-32}$ In the histological evaluation of rectal biopsy specimens Frei and Morson ${ }^{32}$ reported a diagnostic accuracy for Crohn's disease of $37 \%$ and for ulcerative colitis of about $67 \%$. In our study the diagnostic accuracy for Crohn's disease was higher compared with that of both Frei and Morson and Hill et $a l,{ }^{32}{ }^{33}$ as shown in Table IV. However, for the histological features which they used to diagnose Crohn's disease or ulcerative colitis, no probabilities were mentioned. In a previous study of Hill $\mathrm{et} \mathrm{al},{ }^{33}$ though, only $15 \%$ of the first rectal biopsy specimens from clinically defined Crohn's disease patients had the characteristic histological features of Crohn's disease (severe mucosal inflammation, submucosal inflammation, ulcers, and (micro)granulomas). In the present study only three CIBD patients (one Crohn's disease (5\%) and two ulcerative colitis (8\%)) were incorrectly classified as non-CIBD - fewer than reported by Hill et al..$^{33}$ In $75 \%$ of the first rectal biopsy specimens Hill et al reported no distinct abnormalities, while in the study of Frei and Morson ${ }^{32}$ the histological evaluation of first rectal biopsy specimens showed no mucosal abnormalities in only $26 \%$ of the Crohn's disease patients and $8 \%$ of the ulcerative colitis patients. This high percentage of false negatives in comparison to our study could be attributed to a sampling error inherent in the diagnosis of Crohn's disease, a disease with a discontinuous and patchy nature.

Our better diagnostic accuracy rates, as well as the lower false positive and false negative rates can be explained by the fact that we used multiple colonic biopsy specimens from different sites rather than only one rectal biopsy specimen.

It should be emphasised that the various features identified in this study as useful in distinguishing CIBD from non-CIBD and Crohn's disease from ulcerative colitis are the result of discriminant analysis and not an intuitive selection of collective features. 'Blind' histological evaluation of biopsy specimens eliminated the bias of clinical input and provided

TABLE IV Diagnostic accuracy (\%) in published studies compared with that in this study

\begin{tabular}{|c|c|c|c|c|c|c|}
\hline & & \multicolumn{2}{|c|}{ Diagnosis } & \multirow{2}{*}{$\begin{array}{l}\text { CIBD } \\
\text { indeterminate }\end{array}$} & \multirow[b]{2}{*}{ Normal } & \multirow[b]{2}{*}{ Infectious } \\
\hline & & Correct & Incorrect & & & \\
\hline \multirow[t]{2}{*}{ Frei and Morson ${ }^{32}$} & Crohn's disease & 37 & 0 (as ulcerative colitis) & 37 & 26 & 0 \\
\hline & Ulcerative colitis & 67 & 8 (as Crohn's disease) & 14 & 8 & 3 \\
\hline \multirow[t]{2}{*}{ Jenkins $^{30}$} & Crohn's disease & 77 & 23 (as ulcerative colitis) & $\star$ & * & ^ \\
\hline & Ulcerative colitis & 71 & 29 (as Crohn's disease) & * & $\star$ & $\star$ \\
\hline \multirow[t]{2}{*}{ Thompson et $a l^{31}$} & Crohn's disease & 45 & 25 (as ulcerative colitis) & $\star$ & 5 & 25 \\
\hline & Ulcerative colitis & 70 & 10 (as Crohn's disease) & $\star$ & 10 & 10 \\
\hline \multirow[t]{2}{*}{ Present study } & Crohn's disease & 70 & 10 (as ulcerative colitis) & 20 & $\star$ & $\star$ \\
\hline & Ulcerative colitis & 75 & 5 (as Crohn's disease) & 20 & $\star$ & $\star$ \\
\hline
\end{tabular}

^Category was not included. 
objective confirmation of the features that have predictive value. The results of our study, however, also have limitations. Firstly, it must be emphasised that only four groups of subjects (patients with Crohn's disease, ulcerative colitis, and diverticular disease, and healthy controls) were included and that several entities were not encompassed. For instance, we had no cases of infectious, ischaemic, radiation, or pseudomembranous colitis in our study, though it is unlikely that different features will emerge from the analysis when these diseases are included because the discriminant histological features identified in our study are not typical for these diseases. Secondly, the patients in this investigation were only clinically well defined and prospectively biopsied.

The results from this study suggest that the pathologist is dependent on the presence of only a few reproducible histological features for a reliable classification of Crohn's disease and ulcerative colitis. A higher diagnostic accuracy rate might be achieved by additional counting of cells containing immunoglobulin. In earlier studies differences in the number of such cells have been found in mucosal biopsies of Crohn's disease and ulcerative colitis patients. ${ }^{3+38}$ Whether counting cells containing immunoglobulin indeed has additional diagnostic value for the patient in the differential diagnosis of Crohn's disease and ulcerative colitis has been investigated in a concomitant study..$^{39}$

We thank Mr E Noteboom for skilful statistical help.

1 Morson BC, Dawson IMP. Gastrointestinal pathology. Oxford: Blackwell Scientific, 1979: 523-61.

2 Morson BC. Histopathology of Crohn's disease. Scand $\mathcal{f}$ Gastroenterol 1971; 6: 573-5.

3 Whitehead R. Major problems in pathology, vol 3. Mucosa biopsy of the gastrointestinal tract. Philadelphia: WB Saunders, 1989: 209-57.

4 Pathology of the colon, small intestine, and anus. In: Norris HT, ed. Contemporary issues in surgical pathology. New York Churchill Livingstone, 1983; 2: 1-21.

5 Lennard-Jones JE, Lockhart-Mummery HE, Morson BC. Clinical and pathological differentiation of Crohn's disease and proctocolitis. Gastroenterology 1968; 54: 1162-70.

6 Morson BC. Pathology. In: Goligher JC, de Dombal FT, McK Watts J, Watkinson G, eds. Ulcerative colitis. London: Baillière, 1968: 5-31

7 McGovern VJ. The differential diagnosis of colitis. In Sommers SC, ed. The pathology annual. New York: Field and Woods, $1969 ; 4$ : 127-58.

8 Morson BC. Rectal and colon biopsy in inflammatory bowel disease. Am F Gastroenterol 1977; 67: 417-26.

9 McGovern VJ, Goulston SJM. Crohn's disease of the colon. Gut 1968; 9: 164-76.

10 Silcocks PBS. Measuring repeatability and validity of histological diagnosis - a brief review with some practical logical diagnosis - a brief review with
examples. F Clin Pathol 1983; 36: 1269-75.

11 Stenkvist B, Bengtsson E, Eriksson O. Histopathological systems of breast cancer classification: reproducibility and clinical significance. $\mathcal{F}$ Clin Pathol 1983; 36: 392-8.

12 Thomas GDH, Dixon MF, Smeeton NC, Williams NS Observer variation in the histological grading of recta carcinoma. F Clin Pathol 1983; 36: 385-91.

13 Robertson AJ, Anderson JM, Swanson Beck J, et al. Observer variability in histopathological reporting of cervical biopsy specimens. F Clin Pathol 1989; 42: 231-8.

14 Surawicz CM, Belic L. Rectal biopsy helps to distinguish acute self-limited colitis from idiopathic inflammatory bowel disease. Gastroenterology 1984; 86: 104-13.
15 Goldman $H$. Acute versus chronic colitis: how and when to distinguish by biopsy. Gastroenterology 1984; 86: 199-201.

16 Cook MG, Dixon MF. An analysis of the reliability of detection and diagnostic value of various pathological features in Crohn's disease and ulcerative colitis. Gut 1973; 14: $255-62$.

17 Giard RWM, Hermans J, Ruiter DJ, Hoedemaker PhJ Variations in histopathological evaluation of nonneoplasmatic colonic mucosal abnormalities; assessment and clinical significance. Histopathology 1985; 9: 535-41.

18 Schroeder KW, Tremaine WJ, Ilstrup DM. Coated oral 5aminosalycylic acid therapy for mildly to moderately active aminosalycylic acid therapy for mildly to moderately active
ulcerative colitis; a randomized study. $N E n g l \mathcal{F} M$ ed 1987 ; ulcerative co

19 Harvey RF, Bradshaw JM. A simple index of Crohn's disease activity. Lancet 1980; i: 514 .

20 Surawicz CM, Meisel JL, Ylvisaker T, Saunders DR, Rubin $\mathrm{CE}$. Rectal biopsy in the diagnosis of Crohn's disease: value of multiple biopsies and serial sectioning. Gastroenterology 1981; 81: 66-71.

21 Nostrant TT, Kumar NB, Appelman HD. Histopathology differentiates acute self-limited colitis from ulcerative colitis. Gastroenterology 1987; 92: 318-28

22 Rotterdam H, Korelitz BI, Sommers SC. Microgranulomas in grossly normal rectal mucosa in Crohn's disease. Am 7 Clin Pathol 1977; 67: 550-4.

23 Korelitz BI, Sommers SC. Differential diagnosis of ulcerative and granulomatous colitis by sigmoidoscopy, rectal biopsy and cell counts of rectal mucosa. Am $\mathcal{F}$ Gastroenterol 1974; 61: 460-9.

24 Sommers SC, Korelitz BI. Mucosal-cell counts in ulcerative and granulomatous colitis. Am $\mathcal{F}$ Clin Pathol 1975; 63: $359-65$.

25 Yardley JH, Hamilton SR. Focal non-specific inflammation (FNI) in Crohn's disease. In: Pena AS, et al, eds. Recent advances in Crohn's disease. Den Haag: Martinus Nijhoff, 1981: $62-6$.

26 Riddel RH, Goldman H, Ransohoff DF, et al. Dysplasia in inflammatory bowel disease: Standardized classification with pro
$931-68$.

27 Dixon WJ, ed. BMDP biomedical computer programs. Berkeley: University of California Press, 1983.

28 Landis JR, Koch GG. The measurement of observer agreement for categorical data. Biometrics 1977; 33: 159-74.

29 Jenkins D, Goodall A, Drew K, Scott BB. What is colitis? Statistical approach to distinguish clinically important change in rectal biopsy specimens. $\mathcal{F}$ Clin Pathol 1988; 41 : $72-9$.

30 Jenkins D. Computing and histopathology of intestinal inflammation. In: Vicery FR, ed. Computers in gastroenterology. London: Springer Verlag, 1988: 193-204.

31 Thompson EM, Price AB, Altman DG, Sowter C, Slavin G. Quantitation in inflammatory bowel disease using computerized interactive image analysis. $\mathcal{f}$ Clin Pathol 1985; 38 : 631-8.

32 Frei JV, Morson BC. Medical audit of rectal biopsy diagnosis of inflammatory bowel disease. F Clin Pathol 1982; 35: 341-4.

33 Hill RB, Thomas HK, Hansen RN. Clinical usefulness of rectal biopsy in Crohn's disease. Gastroenterology 1979; 77: 938-44.

34 Green FHY, Fox H. The distribution of mucosal antibodies in the bowel of patients with Crohn's disease. Gut 1975; 16: the bowel

35 Rosekrans PCM, Meijer CJLM, Van der Wal AM, Cornelissen $\mathrm{CJ}$, Lindeman J. Immunoglobulin containing cells in inflammatory bowel disease of the colon: a morphometric and immunohistochemical study. Gut 1980; 21: 941-7.

36 Meuwissen SGM, Feltkamp-Vroom TM, Brutel de la Riviere, von den Borne AEGK, Tytgat GN. Analysis of the lymphoplasmacytic infiltrates in Crohn's disease with special reference to identification of lymphocytic subpopulations. Gut 1976; 17: 770-80.

37 Van Spreeuwel JP, Meijer CJLM, Rosekrans PCM, Lindeman J. Immunoglobulin-containing cells in gastrointestinal J. Immunoglobulin-containing cells in gastrointestinal pathology: diagnostic implications. In: Sommers SC, Rosen
PR, Fechner RE, eds. Pathology Annual. Norwalk, PR, Fechner RE, eds. Pathology Annual. Norwalk, 295-311

38 Scott BB, Goodall A, Stephenson PM, Jenkins D. Rectal mucosal plasmacells in inflammatory bowel disease. Gut 1983; 24: 519-24.

39 Seldenrijk CA, Meuwissen SGM, Schipper NW, Morson BC, Lindeman J, Meijer CJLM. The value of counting colonic mucosal immunoglobulin containing cells for the differential diagnosis of chronic inflammatory bowel disease. $\mathcal{F}$ Clin Path (in press). 